\title{
Cyclic peroxides and related initiating systems for radical polymerization of methyl methacrylate
}

\author{
R. M. Islamova, ${ }^{a, b \star}$ O. I. Ishkinina, ${ }^{a}$ S. V. Nazarova, ${ }^{a}$ O. N. Chupakhin, ${ }^{c}$ I. A. Utepova, ${ }^{c}$ \\ N. M. Andriyashina, ${ }^{a}$ and A. O. Terent 'ev ${ }^{d}$ \\ ${ }^{a}$ Institute of Organic Chemistry, Ufa Scientific Center, Russian Academy of Sciences, \\ 71 prosp. Oktyabrya, 450054 Ufa, Russian Federation. \\ Fax: +7(347) 235 6066. E-mail: rmislamova@mail.ru \\ ${ }^{b}$ Bashkir State Agrarian University, \\ 34 ul. 50 let Oktyabrya, 450001 Ufa, Russian Federation \\ ${ }^{c}$ Ural Federal University named after the First President of Russia B. N. Yeltsin, \\ 19 ul. Mira, 620002 Yekaterinburg, Russian Federation \\ ${ }^{d} N$. D. Zelinsky Institute of Organic Chemistry, Russian Academy of Sciences, \\ 47 Leninsky prosp., 119991 Moscow, Russian Federation
}

\begin{abstract}
Cyclic peroxides as initiators for the radical polymerization of methyl methacrylate were proposed. The initial rates, initiation rates, and effective activation energies of polymerization initiated by cyclic peroxides and cyclic peroxide-1-pyridyl-2-ferrocene systems were determined. The radical yields to the volume upon the thermal decomposition of cyclic peroxides and their catalytic decomposition in the presence of 1-pyridyl-2-ferrocene were determined. In combination with 1-pyridyl-2-ferrocene cyclic peroxides form efficient initiating systems favoring an increase in the polymerization rate, a decrease in the molecular weights, and an increase in syndiotacticity of the synthesized poly(methyl methacrylate).
\end{abstract}

Key words: radical polymerization, cyclic peroxides, initiators, 1-pyridyl-2-ferrocene, initiating systems, kinetic parameters, molecular characteristics.

One of the most popular methods for the production of polymers in industry is radical polymerization often using peroxides as initiators. ${ }^{1}$ More than $50 \%$ of volumes of peroxides produced in the world industry are applied for the production of polymer materials by the radical polymerization method. ${ }^{2}$ Numerous monographs, reviews, and articles devoted to the study of initiating/catalytic systems based on metal-containing compounds and traditional peroxides for radical polymerization were published. $\mathbf{1}^{\mathbf{1} 3-6}$

We have earlier developed ${ }^{6}$ efficient initiating systems based on various azinyl ferrocene derivatives in combination with benzoyl peroxide (BP), which favor an increase in the initial and overall rates of methyl methacrylate (MMA) polymerization and a decrease in the synthesis temperature and effective activation energy of the process. In addition, it was shown that the proposed initiating systems affect the properties of synthesized poly(methyl methacrylate) (PMMA), viz., stereoregularity and thermal stability. ${ }^{6}$ The influence of the nature of the ligand environment of substituted ferrocenes on MMA polymerization was established.

The process of MMA polymerization in the presence of new cyclic peroxides, 3,6-dicyclohexyl-9,9'-dimethyl1,2,4,5,7,8-hexaoxonane (1), 3,6-dicyclododecyl-9-cyclohexyl-1,2,4,5,7,8-hexaoxonane (2), and 3,6-dicyclohexyl9-cyclododecyl-1,2,4,5,7,8-hexaoxonane (3) (first proposed as initiators of radical polymerization), in combination with 1-pyridyl-2-ferrocene (PFc) was studied to extend

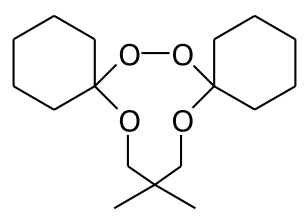

1

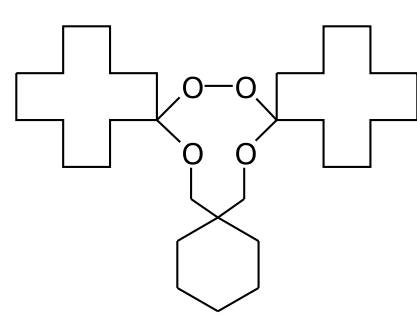

2

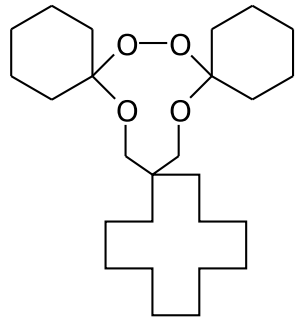

3

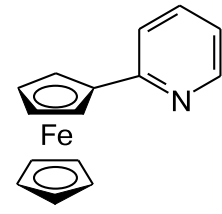

PFC

Published in Russian in Izvestiya Akademii Nauk. Seriya Khimicheskaya, No. 5, pp. 1282-1286, May, 2013.

1066-5285/13/6205-1282 C 2013 Springer Science+Business Media, Inc. 
the range of initiators used and to establish the influence of the nature of the peroxide initiator. The choice of $\mathrm{PFc}$ is caused by its high reactivity in polymerization processes compared to other heterocyclic ferrocene derivatives studied. ${ }^{6}$

\section{Experimental}

Prior to use methyl methacrylate (Fluka) was distilled two times under reduced pressure, b.p. $48^{\circ} \mathrm{C}$ at $p=140$ Torr. Cyclic peroxides ${ }^{7}$ and PFc (see Ref. 8 ) were synthesized and purified according to earlier described procedures. Purity of the used reagents was monitored by ${ }^{13} \mathrm{C}\left\{{ }^{1} \mathrm{H}\right\}$ NMR spectroscopy.

For bulk polymerization, the reaction mixture was poured into an ampule, the solution was degassed by three freezing-evacuation-thawing out cycles to a residual pressure of $1.3 \mathrm{~Pa}$, and the ampule was sealed off. Then the ampule was placed in a thermostat with the temperature $(60-90) \pm 0.1^{\circ} \mathrm{C}$ and kept until the corresponding conversion was achieved. Then the ampule was cooled and opened. The polymer product formed was dissolved in acetone and precipitated with a 10-15-fold excess of methanol. Residues of the initiator and a metal complex substance were removed from the samples using triple reprecipitation. The kinetics of the process at deep conversions (glycerol was used as a sealing liquid) was studied by the dilatometric method. ${ }^{9}$

Molecular weight characteristics of polymers (weight average $\left(M_{\mathrm{w}}\right)$ and numerical average $\left(M_{\mathrm{n}}\right)$ molecular weights) were determined by GPC on a Waters GPC 2000 System liquid chromatograph (THF as an eluent, flow rate $0.5 \mathrm{~mL} \mathrm{~min}^{-1}$ ) equipped with a differential refractometer and columns of the HT-3, HT-4, and HT-6 type packed with Styragel. The system of columns was calibrated by polystyrene standards with $M_{\mathrm{w}} / M_{\mathrm{n}} \leq 1.2 .{ }^{10}$

The ${ }^{1} \mathrm{H}$ NMR spectra of polymer solutions in $\mathrm{CDCl}_{3}$ were recorded at $25^{\circ} \mathrm{C}$ on a Bruker AM-500 spectrometer (Germany) relative to $\mathrm{Me}_{4} \mathrm{Si}$ as an internal standard. The content of triads was calculated from the integral height of the signal from the $\alpha$-methyl group (iso-, hetero-, and syndio- at $\delta 1.17,0.98$, and 0.79 , respectively). ${ }^{11}$

The radical yields to the volume upon the thermal decomposition of peroxide 2 and of peroxide 2 in the presence of PFc were determined from the consumption of the inhibitor ( $\beta$-naphthol $)^{2}$ in temperature ranges of $130-180$ and $80-130^{\circ} \mathrm{C}$, respectively. The solvent $(5 \mathrm{~mL})$ was placed in a $20-\mathrm{mL}$ reactor equipped with a reflux condenser and a capillary for inert gas blowing, and a weighed sample of $\beta$-naphthol $\left(2.4 \cdot 10^{-2} \mathrm{~mol} \mathrm{~L}^{-1}\right)$ was added. The solution was kept for $5 \mathrm{~min}$ at the experimental temperature with continuous blowing with an inert gas, and then a solution of peroxide $\left(0.4 \cdot 10^{-2} \mathrm{~mol} \mathrm{~L}^{-1}\right)$ was injected. After the addition of peroxide, samples were taken at certain time intervals and analyzed to the content of $\beta$-naphthol. It was shown in preliminary experiments that no changes in the $\beta$-naphthol concentration were observed at $180^{\circ} \mathrm{C}$ for $6 \mathrm{~h}$.

The spectrophotometric determination of $\beta$-naphthol is based on the cross-coupling of $\beta$-naphthol with diazotized sulfanilic acid. ${ }^{\mathbf{1 2}, 13}$ The reaction product is an azo compound with a high molar absorption coefficient. Sulfanilic acid (1.25 g) was dissolved on heating in $5 \mathrm{M} \mathrm{HCl}(125 \mathrm{~mL})$, and the solution was diluted to a volume of $500 \mathrm{~mL}$. A $0.7 \%$ solution of $\mathrm{NaNO}_{2}(5 \mathrm{~mL})$ cooled to $5{ }^{\circ} \mathrm{C}$ and $3-5$ droplets of a $1 \%$ solution of $\mathrm{KBr}$ (to accelerate the diazotization process) were added to $20 \mathrm{~mL}$ of the obtained solution of sulfanilic acid also cooled to $5^{\circ} \mathrm{C}$. The reagent was stored for $24 \mathrm{~h}$ at $0{ }^{\circ} \mathrm{C}$.
The studied solution of $\beta$-naphthol $(4 \mu \mathrm{L})$ was added to a solution of $\mathrm{NaHCO}_{3}(3 \mathrm{~mL})$, the solution was stirred, and diazotized sulfanilic acid $(\sim 10 \mu \mathrm{L})$ was introduced (after the addition, $\mathrm{pH} \approx 7$ ). The absorbance of the solution was measured at $480 \mathrm{~nm}$ relative to water after a constant value was attained. The concentration of $\beta$-naphthol $\left(\mathrm{mol} \mathrm{L}^{-1}\right)$ was calculated using the formula

$$
[\ln \mathrm{H}]=A V_{0} /(\varepsilon l V),
$$

where $A$ is the absorbance, $V_{0}$ is the volume of a solution of $\mathrm{NaHCO}_{3}(3 \mathrm{~mL}), V$ is the volume of the sample $(4-6 \mu \mathrm{L})$, $\varepsilon$ is the molar absorption coefficient of the azo compound (21 $800 \mathrm{~L} \mathrm{~mol}^{-1} \mathrm{~cm}^{-1}$ ), and $l$ is the optical length of the cell $(1 \mathrm{~cm})$. The obtained value of $\varepsilon$ coincides with the literature data: at $\mathrm{pH}=7.1 \varepsilon=22000$ (see Ref. 12) and 21800 (see Ref. 13) $\mathrm{L} \mathrm{mol}^{-1} \mathrm{~cm}^{-1}$.

The physicochemical characteristics of purified distilled solvents (acetone, THF, deuterated chloroform, and methanol), as well as glycerol used as a sealing liquid, corresponded to the literature data. ${ }^{\mathbf{1 4}}$

\section{Results and Discussion}

The polymerization of MMA was studied in the presence of cyclic peroxides only for a correct comparison of the influence of the initiating systems $\mathrm{PFc}-$ cyclic peroxide. It was found that used peroxides $\mathbf{1}-\mathbf{3}$ make it possible to conduct polymerization in high yields with retention of relatively high rates of the process (Fig. 1). The optimum temperature for PMMA synthesis initiated by cyclic peroxides is $80^{\circ} \mathrm{C}$. The data in Fig. 1 show that peroxide 1 is the most active among the peroxides obtained, which can be due to specific features of its structure. Molecules 2 and $\mathbf{3}$ have more bulky cyclododecyl substituents than $\mathbf{1}$ containing cyclohexyl fragments in the structure.

The study of the dependence of the overall polymerization rate on the concentration of cyclic peroxides showed that the rate of MMA polymerization increases with an increase in the peroxide concentration in the system

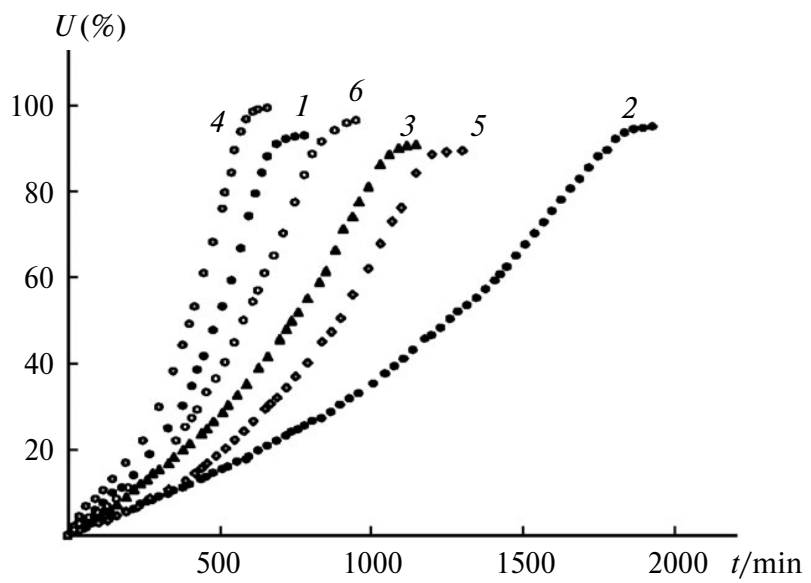

Fig. 1. Conversion $(U)$ vs polymerization time for MMA at $80^{\circ} \mathrm{C}$ in the presence of peroxides 1 (1), 2 (2), and 3 (3) and systems $\mathrm{PFc}-1$ (4), $\mathrm{PFc}-2(5)$, and $\mathrm{PFc}-3(6) ;[1]=[2]=[3]=[\mathrm{PFc}]=$ $=1.0 \cdot 10^{-3} \mathrm{~mol} \mathrm{~L}^{-1}$. 
from $0.5 \cdot 10^{-3}$ to $3.0 \cdot 10^{-3} \mathrm{~mol} \mathrm{~L}^{-1}$ due to an increase in the number of free radicals capable of initiating the process.

The introduction of the metal complex additive PFc into the reaction mixture of MMA polymerization initiated by cyclic peroxides shortens the time of achievement of the ultimate conversion (see Fig. 1). Evidently, PFc forms initiating systems with all cyclic peroxides studied, as well as in the case of using PB as an initiator. ${ }^{6}$

The introduction of PFc resulted in an increase in the initial rate of MMA polymerization $\left(W_{0}\right)$ initiated by peroxide 2 in the whole temperature range $\left(60-90^{\circ} \mathrm{C}\right.$, Table 1$)$. It is seen from the tabulated data that $W_{0}$ increases with an increase in the additive content (at a fixed concentration of peroxide 2 equal to $\left.1.0 \cdot 10^{-3} \mathrm{~mol} \mathrm{~L}^{-1}\right)$. The reaction orders of polymerization with respect to the additive (PFc) and initiator (2) were 0.5 , which is typical of radical polymerization with bimolecular termination of propagating chains. ${ }^{9}$ The initiation rate in the presence of PFc determined at $80^{\circ} \mathrm{C}$ is by $\sim 2.7$ times higher than that in the case of using peroxide 2 only and is equal to $8.4 \cdot 10^{-9} \mathrm{~mol} \mathrm{~L}^{-1} \mathrm{~s}^{-1}$. The ratio of rate constants of chain propagation and termination $k_{\mathrm{p}} k_{\mathrm{t}}^{-0.5}$ in the $2-\mathrm{PFc}$ system is equal to the value determined in the case of initiating by peroxide 2 only, being $0.1 \mathrm{~L}^{0.5} \mathrm{~mol}^{-1} \mathrm{~s}^{-0.5}$. The effective activation energy of MMA polymerization in the presence of PFc calculated from the temperature dependences is $54 \pm 4 \mathrm{~kJ} \mathrm{~mol}^{-1}$, which is by $\sim 1.5$ times lower than that upon the introduction of peroxide 2 only. The decrease in the effective activation energy indicates the possibility to carry out polymerization initiated by the $2-\mathrm{PFc}$ system at relatively lower temperatures of synthesis that in the presence of peroxide 2 only.

The initiating ability of peroxide $\mathbf{2}$ and $\mathbf{2}-\mathrm{PFc}$ system was also determined by the consumption of the inhibitor. The kinetic curves of $\beta$-naphthol consumption are de-

Table 1. Kinetic parameters for MMA polymerization in the presence of peroxide $\mathbf{2}$ and $\mathrm{PFc}$ at different temperatures $\left(T_{\mathrm{p}}\right)$ (monomer conversion is $5-7 \%$ )

\begin{tabular}{|c|c|c|c|}
\hline \multirow[t]{2}{*}{$T_{\mathrm{p}} /{ }^{\circ} \mathrm{C}$} & {$[\mathrm{PFc}] \cdot 10^{3}$} & {$[2] \cdot 10^{3}$} & \multirow{2}{*}{$\begin{array}{c}W_{0} \cdot 10^{3} \\
/ \mathrm{mol} \mathrm{L}^{-1} \min ^{-1}\end{array}$} \\
\hline & \multicolumn{2}{|c|}{$\mathrm{mol} \mathrm{L}^{-1}$} & \\
\hline \multirow[t]{4}{*}{60} & 0 & 1.0 & 0.6 \\
\hline & 0.5 & 1.0 & 1.2 \\
\hline & 1.0 & 1.0 & 1.9 \\
\hline & 2.0 & 1.0 & 2.2 \\
\hline \multirow[t]{6}{*}{75} & 0 & 1.0 & 1.6 \\
\hline & 0.5 & 1.0 & 2.4 \\
\hline & 1.0 & 1.0 & 3.7 \\
\hline & 2.0 & 1.0 & 4.6 \\
\hline & 1.0 & 0.5 & 2.5 \\
\hline & 1.0 & 2.0 & 5.1 \\
\hline \multirow[t]{4}{*}{90} & 0 & 1.0 & 4.4 \\
\hline & 0.5 & 1.0 & 6.1 \\
\hline & 1.0 & 1.0 & 8.2 \\
\hline & 2.0 & 1.0 & 11.4 \\
\hline
\end{tabular}

scribed by the first-order equation in the whole temperature range studied. The rate constant for radical generation $\left(k_{\mathfrak{j}}\right)$ in the presence of $\mathrm{PFc}$ is by $\sim 4$ times higher. So, at $80^{\circ} \mathrm{C} k_{\mathrm{i}}=0.64 \cdot 10^{-5}$ and $2.69 \cdot 10^{-5} \mathrm{~s}^{-1}$ for the thermolysis of peroxide 2 and $\mathbf{2}-\mathrm{PFc}$ system, respectively. The total radical yield to the volume upon the thermal decomposition of peroxide $\mathbf{2}$ in the studied temperature range is nearly quantitative $(\mathrm{e} \approx 1)$. In the presence of $\mathrm{PFc}$, the yield is much lower but increases with the temperature increase, for instance, $\mathrm{e}=0.30\left(130^{\circ} \mathrm{C}\right)$ and $0.48\left(150^{\circ} \mathrm{C}\right)$.

It was assumed that ferrocene and $\mathrm{BP}$ react to form iron(II) benzoate, which catalyzes the decomposition of BP. ${ }^{15}$ The complex formation of ferrocene and BP was studied. ${ }^{\mathbf{1 6}}$ It is also known that tertiary aromatic amines are activators of polymerization of vinyl monomers and catalyze the decomposition of peroxide initiators. ${ }^{17}$ The study of the systems based on BP and heterocyclic ferrocene derivatives found the synergetic catalytic effect of two groups, metallocene and nitrogen-containing, combined at the molecular level. ${ }^{6,18}$ Probably, similar reactions can occur between the studied peroxides and PFc.

The molecular weights (MW) of the PMMA samples based on peroxide 2 are given in Table 2. It is seen from the tabulated data that the MW of the polymers increase with an increase in the conversion. The MW of the polymers synthesized on the basis of cyclic peroxides are higher than those when BP and systems based on BP and ferrocene or its heterocyclic derivatives are used as initiators. $^{\mathbf{1 8}}$ The polydispersion coefficients for PMMA are 2.1-2.6. The molecular weight of PMMA obtained in the presence of the 2-PFc system decreases compared to the MW of the samples synthesized in the presence of peroxide 2 only (see Table 2). The polydispersion coefficients of the samples do not exceed 2.3. The molecular weight distribution curves of PMMA synthesized on both initiating systems are unimodal, and they shift to the highermolecular-weight range with an increase in the conversion.

The content of the syndiotactic fragments in the polymer chain of PMMA in the presence of cyclic peroxides is $55-58 \%$

Table 2. Molecular weight characteristics of PMMA obtained in the presence of peroxide 2 and $\mathrm{PFc}$ at $80^{\circ} \mathrm{C} v s$ monomer conversion; [2] $=1.0 \cdot 10^{-3} \mathrm{~mol} \mathrm{~L}^{-1}$

\begin{tabular}{lcccc}
\hline $\begin{array}{l}{[\mathrm{PFc}] \cdot 10^{3}} \\
/ \mathrm{mol} \mathrm{L}^{-1}\end{array}$ & $\begin{array}{c}\text { Conver- } \\
\text { sion }(\%)\end{array}$ & $M_{\mathrm{w}} \cdot 10^{-3}$ & $M_{\mathrm{n}} \cdot 10^{-3}$ & $M_{\mathrm{w}} / M_{\mathrm{n}}$ \\
\hline 0 & 10 & 2790 & 1340 & 2.1 \\
& 20 & 3420 & 1400 & 2.4 \\
& 40 & 4310 & 2060 & 2.1 \\
& 60 & 5540 & 2140 & 2.6 \\
1.0 & 80 & 5640 & 2520 & 2.2 \\
& 10 & 2340 & 1150 & 2.0 \\
& 20 & 2770 & 1230 & 2.3 \\
& 40 & 3410 & 1640 & 2.1 \\
& 60 & 3540 & 1720 & 2.1 \\
& 80 & 3670 & 1900 & 1.9 \\
\hline
\end{tabular}


Table 3. Microstructure of PMMA obtained in the presence of peroxide 2 and $\mathrm{PFc}$ at $80^{\circ} \mathrm{C}$; [2] $=$ $=1.0 \cdot 10^{-3} \mathrm{~mol} \mathrm{~L}^{-1}$

\begin{tabular}{lcccc}
\hline$[\mathrm{PFc}] \cdot 10^{3}$ & $\begin{array}{c}\text { Conver- } \\
\text { sion }(\%)\end{array}$ & \multicolumn{3}{c}{ Content of triads (\%) } \\
\cline { 3 - 5 } & & Syndio- & Hetero- & Iso- \\
\hline 0 & 10 & 58 & 37 & 5 \\
& 20 & 55 & 39 & 6 \\
& 40 & 58 & 37 & 5 \\
& 60 & 59 & 36 & 5 \\
1.0 & 80 & 58 & 37 & 5 \\
& 10 & 66 & 31 & 3 \\
& 20 & 64 & 34 & 2 \\
& 40 & 67 & 29 & 4 \\
& 60 & 67 & 30 & 3 \\
& 80 & 66 & 31 & 3 \\
\hline
\end{tabular}

(Table 3) as in the polymer obtained ${ }^{\mathbf{1 8}}$ on the basis of BP. In the presence of $\mathrm{PFc}$, stereoregularity of synthesized PMMA increases, The content of the syndiotactic fragments in the polymer chain increases by 8-9\% (see Table 3 ).

Evidently, the change in the molecular weight characteristics and stereochemical composition are caused by the influence of the metal complex additive on the chain propagation and termination stages due to the formation of active centers with the growing macroradical, metallocene, and monomer. ${ }^{19}$ The coordination of the polymer radical and monomer through the metal atom of the complexing molecule favors the ordering of monomer addition. At the same time, the complex centers formed cannot participate in the reactions of square chain termination, which makes the termination reaction pseudo-monomolecular, most likely, and decreases the MW of the obtained polymers. Similar regularities of changing the molecular weight characteristics and stereoregularity are observed for MMA polymerization in the presence of heterocyclic ferrocene derivatives and $\mathrm{BP}^{6,18}$ and in the presence of new initiating systems proposed in this work. This assumes that the process proceeds, in this case, via analogous coordination radical mechanism.

So, the use of cyclic peroxides allows one to carry out MMA polymerization in the temperature range $60-90{ }^{\circ} \mathrm{C}$ in good yields with retention of relatively high rates of the process. The PMMA samples synthesized using cyclic peroxides are not inferior in molecular characteristics to the polymers obtained on the basis of BP traditionally used in industry and even surpass them in particular parameters. In particular, the MW increase and the polydispersion of PMMA decrease, which should improve the exploitation characteristics of the polymer products. In combination with $\mathrm{PFc}$, cyclic peroxides, as $\mathrm{BP},{ }^{6,18}$ form initiating systems that favor an enhancement of the MMA polymerization rate, a decrease in the MW of the obtained polymers, and an increase in the stereoregularity of
PMMA, which is evidently caused by the influence of the metallocene derivative at the stages of chain propagation and termination due to the formation of complex active sites with the growing macroradical and monomer molecule.

\section{References}

1. M. K. Mishra, Y. Yagci, Handbook of Vinyl Polymers: Radical Polymerization, Process, and Technology, Taylor and Francis Group, Boca Raton, 2009, 746 pp.

2. Z. Rappoport, The Chemistry of Peroxides, Vol. 2, Part 1, John Wiley and Sons Ltd, Chichester, 2006, 1518 pp.

3. F. Lena, K. Matyjaszewski, Progress Polym. Sci., 2010, 35, 959.

4. M. Ouchi, T. Terashima, M. Sawamoto, Chem. Rev., 2009, 109, 4963.

5. D. F. Grishin, Vysokomol. Soedin., 2011, 53, 1168 [Polym. Sci. (Engl. Transl.), 2011, 53].

6. R. M. Islamova, O. I. Golovochesova, Yu. B. Monakov, I. A. Utepova, A. A. Musikhina, O. N. Chupakhin, Vysokomol. Soedin., 2010, 52, 2184 [Polym. Sci. (Engl. Transl.), 2010, 52].

7. A. O. Terent'ev, M. M. Platonov, E. J. Sonneveld, R. Peschar, V. V. Chernyshev, Z. A. Starikova, G. I. Nikishin, J. Org. Chem., 2007, 72, 7237.

8. O. N. Chupakhin, I. A. Utepova, I. S. Kovalev, V. L. Rusinov, Z. A. Starikova, Eur. J. Org. Chem., 2007, 5, 857.

9. G. P. Gladyshev, Polimerizatsiya vinilovykh monomerov [Polymerization of Vinyl Monomers], Nauka, Alma-Ata, 1964, 322 pp. (in Russian).

10. E. L. Styskin, L. B. Itsikson, E. V. Braude, Prakticheskaya vysokoeffektivnaya khromatografiya [Practical High-Performance Chromatography], Khimiya, Moscow, 1986, 290 pp. (in Russian).

11. R. C. Ferguson, J. Am. Chem. Soc., Polym. Prep., 1985, 6, 182.

12. I. M. Korenman, Fotometricheskii analiz. Metody opredeleniya organicheskikh soedinenii [Photometric Analysis. Methods for Determination of Organic Compounds], Khimiya, Moscow, 1975, 44 pp. (in Russian).

13. S. Siggia, Dzh. G. Khana, Kolichestvennyi organicheskii analiz po funktsional'nym gruppam [Quantitative Organic Analysis by Functional Groups], Khimiya, Moscow, 1983, 77 pp. (in Russian).

14. J. Gordon, R. A. Ford, The Chemist's Companion: A Handbook of Practical Data, Techniques and References, Wiley, New York, 1972, 542 pp.

15. P. Kalenda, Eur. Polym. J., 1995, 31, 1099.

16. R. M. Islamova, G. R. Sadykova, Yu. I. Puzin, L. V. Spirikhin, V. A. Kraikin, Yu. B. Monakov, Vysokomol. Soedin., 2008, 50, 938 [Polym. Sci. (Engl. Transl.), 2008, 50].

17. A. N. Pravednikov, S. D. Stavrova, I. P. Chikhacheva, E. P. Efremova, M. G. Eremina, E. N. Budanova, Plast. Massy [Plastics], 1980, 12, 10 (in Russian).

18. R. M. Islamova, Doct. Sci. (Chem.) Thesis, Institute of Organic Chemistry, Ufa Scientific Center, Russian Academy of Sciences, Ufa, 2010, 358 pp. (in Russian).

19. Yu. B. Monakov, R. M. Islamova, A. K. Frizen, O. I. Golovochesova, S. V. Nazarova, Mendeleev Commun., 2011, 21, 206.

Received August 20, 2012; in revised form January 23, 2013 